\title{
The magnitude and associated factors of Helicobacter pylori infection among adult dyspeptic patients attending Bokoji Hospital, Southeast Ethiopia
}

\section{Dagaga Kenea ( $\triangle$ Dagagakenea@gmail.com )}

Arsi University https://orcid.org/0000-0001-9586-5880

\section{Mesfin Negawo}

Asella Town Health office

Firaol Lemessa

Arsi University

Solomon Tejineh

Arsi University

\section{Research Article}

Keywords: H. pylori, Dyspepsia, Bokoji Hospital Introduction

Posted Date: June 1st, 2020

DOI: https://doi.org/10.21203/rs.3.rs-31878/v1

License: (c) (1) This work is licensed under a Creative Commons Attribution 4.0 International License.

Read Full License 


\section{The magnitude and associated factors of Helicobacter pylori infection among adult dyspeptic patients attending Bokoji Hospital, Southeast Ethiopia}

Dagaga Kenea ${ }^{1, *}$, Mesfin Negawo ${ }^{2}$, Firaol Lemessa ${ }^{3}$, Solomon Tejineh $^{3}$

${ }^{1}$ Department of medical laboratory Sciences, College of Health Sciences, Arsi University

${ }^{2}$ Asella Town Health Office.

${ }^{3}$ Department of Public Health, College of Health Sciences, Arsi University.

Email Address:

${ }^{1}$ Dagagakenea@gmail.com

2mnegewo@gmail.com

33fir12420@gmail.com

${ }^{3}$ stejineh@yahoo.com

*Corresponding Author (Name: Dagaga Kenea, Email: Dagagakenea@gmail.com

Background: Helicobacter pylori infection is the most common chronic bacterial infection and there were approximately 4.4 billion individuals with $H$ pylori infection worldwide. Among those, hundreds of millions of people develop peptic ulcer disease during their lifetime and still tens of millions might progress to gastric cancer. Hence, early information is very important to prevent upper gastrointestinal complications. Consequently, the current study aimed to assess the magnitude and associated risk factors of Helicobacter pylori infection among adult dyspeptic patients attending Bokoji hospital, Southeast Ethiopia.

Methods: A hospital-based cross-sectional study involving 348 adult dyspeptic patients attending Bokoji hospital was carried out from July 16 to October 31, 2019. About $50 \mathrm{mg}$ of fresh stool and $60 \mu 1$ of capillary blood were collected from each dyspeptic patient and analyzed for detection of Helicobacter pylori antigens, presence of intestinal parasites and ABO blood grouping respectively. Data were entered using Epi Info 7 and Statistical analysis was done using SPSS version 21 and a p-value less than 0.05 was considered as statistically significant.

Results: The overall magnitude of Helicobacter pylori infection was 47.7\%. The magnitude of $\mathrm{H}$. pylori infection was almost two times higher in patients who do not have a habit of handwashing 
after toilet visit than those who wash their hand's habit of handwashing after visiting toilet (AOR 2.241, 95\% CI (1.410, 3.563) and alcohol drinking habit (AOR 1.796, 95\% CI $(1.087,2.968)$.

Conclusions: The magnitude of $H$. pylori was high in the study area and associated with handwashing habits after toilet use and alcohol drinking habits. Therefore, the community could be educated on the handwashing habit to minimize H. pylori infections.

Keywords: H. pylori, Dyspepsia, Bokoji Hospital Introduction

Background : Helicobacter pylori was first identified in 1982 by Australia scientists Dr. Barry Marshall and Dr. Robin Warren, from the stomach of patients with gastritis and stomach ulcers [1]. Three routes of transmission from the stomach of one person to that of another have been described. These were iatrogenic and person to person transmission by either the fecal-oral or oral-oral route [2]. H. pylori have been classified as a class I carcinogen by the International Agency for Research on Cancer (IARC) and currently is considered a necessary but insufficient cause of gastric adenocarcinoma [3].

H. pylori had been involved in the pathogenesis of different digestive tract disorders, such as chronic active gastritis, peptic ulcer, gastric cancer, and mucosa-associated lymphoid tissue lymphoma. Infection with H. pylori is also associated with dyspepsia which is an extremely common disorder, affecting an estimated $25 \%$ of all adults living in the Western developed nations [4]. Even though most people infected with $H$. pylori suffer no related symptoms it increases the risk of gastric cancer. Approximately $95 \%$ of duodenal ulcers and $89 \%$ of all gastric cancers can be attributable to $H$. pylori infection $[3,5]$. The eradication of $H$. pylori reduces gastric cancer risk in previously infected individuals, suggesting that mostly $H$. pylori infection initializes gastric cancer and continued presence is a risk factor for gastric cancer $[6,7]$. The prevalence of gastric and duodenal ulceration has decreased in western Europe and the USA over recent decades, following a decline in the prevalence of $H$. pylori [8] this may think to be caused by the reduced chances of childhood infection due to improved hygiene and sanitation and the active elimination of carrier ship via antimicrobial treatment [9].

According to the Federal Ministry of Health, dyspepsia accounts for $3.6 \%$ and $4.4 \%$ causes of morbidity of all cases among both sexes and females respectively [10]. Also, dyspepsia is one of the commonest complaints in any Ethiopian outpatient department and accounts for $10 \%$ of 
hospital admissions in Ethiopia [11]. Between $80 \%$ and $90 \%$ of all ulcers are caused by or are associated with $\mathrm{H}$. pylori [12]. H. pylori infection was significantly associated with $45.2 \%$ of uninvestigated dyspepsia [13].

The present study was intended to assess the magnitude and associated risk factors of Helicobacter pylori infection among adult dyspeptic patients attending Bokoji Hospital, Southeast Ethiopia, 2019

\section{METHODS}

The hospital-based cross-sectional study design was used to assess the magnitude and associated factors of Helicobacter pylori infection among adult dyspeptic patients attending Bokoji Hospital, Southeast Ethiopia. It was conducted from July, 16 to October 31, 2019.

The sample size was determined using the statistical double population proportion formula using Epi info 7 stat-calculator based on factor associated with $H$. pylori infection from a study done in Butajira, South Ethiopia [14]. After correcting using finite population correction formula and adding $10 \%$ contingency for the non-response rate give the final sample size to be 354 .

All patients with complaints of dyspepsia who are with persistent or recurrent symptoms occurring at least three times per week. Also, whose age was more than 18 years old and those who did not previously treat $H$. pylori eradication therapy were included in the study. Individuals who are unable to communicate due to different illnesses and unable to obtain stool samples were excluded.

A systematic random sampling technique was used to select study units. Three hundred fifty-four (354) dyspeptic patients were selected randomly for this study. The average number of patients with dyspepsia complaints was 18 per day from two months data of last year the same period in all three adult OPDs. Interval $\left(\mathrm{K}^{\text {th }}\right)$ was determined by dividing the number of dyspeptic patients attending the three OPD (792) to the final sample size. Then systematic sampling method will be used for selecting the patients approximately at each $2^{\text {nd }}$ interval by using their numbers at arrival time as sampling frame at central OPD triage. From this average of eight patients were selected per day. Then the patients were provided code in line with its Medical record folder and sent to OPDs for data collection and requested for laboratory investigation after face to face interviews. 


\section{Data collection procedures (instruments, personnel, measurements)}

Three B.Sc. Nurses were used as data a collector, two experienced B. Sc Laboratory Technologists were used for Laboratory examination and one senior laboratory technologist was used as a supervisor. One day intensive training before the actual work was given by investigators and experienced laboratory technologists on data collection principles and laboratory procedures before their participation.

\section{Questionnaire}

A structured questionnaire based on common factors associated were developed. Information on the demographic and socioeconomic, behavioral factors, sources of drinking water and utilization of latrine was obtained using a structured questionnaire. The questionnaire was initially prepared in English, translated into Afan Oromo by language experts and back to English to ensure consistency. Then, the participants were interviewed with regional language, Afan Oromo. To ensure quality control, $5 \%$ of the structured questionnaire was pre-tested in line with laboratory procedures before actual data collection at Gobessa district hospital. The necessary amendment was made on the questionnaires.

\section{Laboratory sample collection and testing}

A fecal specimen consisting of 50 milligrams or pea-sized fresh stool was requested from each study participant. The collected samples were kept in a plastic screw-capped container and transported to the laboratory for examination within ten minutes of delivery.

From each stool sample, a small portion of the fecal material was taken using a sterile applicator stick which was screwed on the collection tube and placed the stick in the tube and tighten securely. The samples were diluted using the extraction buffer contained in a vial and vigorously shaken by hand. The resulting diluted material was added in drops on to the NOVA HPSA test strip and the results were read after 15 to 30 minutes according to the manufacturer's instruction although positive results may be visible in as short as 1-minute time.

Also, a direct wet mount with normal saline $(0.85 \% \mathrm{NaCl}$ solution $)$ was prepared at the study site and examined for the presence of motile intestinal parasites, trophozoites, and eggs under a light microscope at 10X and 40X magnification. Lugol's iodine staining was also used to identify cysts of intestinal parasites [15]. 
Capillary blood samples were collected and tested for ABO blood group phenotype using a hemagglutination test.

At the time of sampling; date of sampling, age, sex, presence or absence of Helicobacter pylori infections, presence or absence of intestinal parasites, blood group and code number was recorded for each study participants in the laboratory record format.

All the laboratory procedures including the collection and handling of specimens were carried out by standard protocol [16]. The entire laboratory procedures including the collection and handling of specimens were also carried out following standard leaf-let of the NOVA HPSA test kit. Care was taken to avoid using the strip beyond the expiration date and reading of the results was done within 15 minutes after the sample was applied. Also, test strips were immediately removed from the test area after interpreting the results to avoid confusion.

To ensure general safety, disposable gloves were worn and universal bio-safety precautions [17] were followed at all times.

\section{Data processing and analysis}

The data were entered into Epi Info 7. Cleaned and checked against the original document before analysis. All statistical analyses were performed using SPSS version 21. Descriptive statistics were used to express the overall prevalence of the infection in percentage. Bivariate and multivariate logistic regressions were fitted to select candidate variables at $(p$-value $\leq 0.25)$ and declare significantly associated variables for final at ( $\mathrm{p}$-value $\leq 0.05$ ) respectively. The $95 \% \mathrm{CI}$ and Odds ratios $(\mathrm{OR})$ were used to show the effect of independent variables on dependent variables.

\section{RESULT}


Among 354 systematically selected adult dyspeptic patients 348 have successfully participated in this study. Thus, the response rate was $98.3 \%$. Six study participants were excluded from the study due to unable to obtain stool samples.

\section{Socio-demographic characteristics of the study participants.}

A total of 354 adult dyspeptic patients were included in the study. About 218 (62.6\%) were females and $130(37.4 \%)$ were males. The majority of the participants were in the age range of 26 to 40 years $158(45.4 \%)$ with a median age of 30 years $( \pm 15 \mathrm{IQR}) .195(56.0 \%)$ were urban residents. Out of the total, $238(68.4 \%)$ of the study participants were married while $89(25.6 \%)$ were single or unmarried. Most of the study participants $230(66.1 \%)$ and $100(28.7 \%)$ were from the Oromo and Amhara ethnic group, respectively. Of the total participants, 100 (28.7\%) and 92 (26.4\%) were achieved primary education and occupationally housewife, respectively. About the family size, $217(62.4 \%)$ of them were living within the family having 1-5 members. About half of the participants had a monthly income of less than 500 Ethiopian Birr (Table 1).

\section{The magnitude of $\boldsymbol{H}$. pylori infection among adult dyspeptic patients visiting Bokoji hospital about Socio-demographic factors.}

The overall magnitude of $H$. pylori infection among all of the study participants was $47.7 \%$

The magnitude of $\mathrm{H}$. pylori infection was assessed by considering the socio-demographic characteristics of the study participants. The study showed that the magnitude of H. pylori infection was higher $82(51.9 \%)$ among study participants who were in the age group between 26 and 40 years and lower $44(41.5 \%)$ among participants aged less than 25 years. The proportion of $\mathrm{H}$. pylori infection in males and females was 61(46.9\%) and 105 (48.2\%), respectively. The infection was higher among urban dwellers $102(52.3 \%)$ and separated marital status 8(61.5\%). Regarding family size, of 218 participants with family members of less or equal to five members living together 113 (51.1\%) were positive for H. pylori (Table 2).

Table 1: Socio-demographic characteristics of adult dyspeptic patients attending Bokoji Hospital, 2019.

\begin{tabular}{rcc}
\hline Characteristics & Frequency & Percent \\
\hline The age group of respondents & & \\
$18-25$ years & 104 & $29.9 \%$ \\
$26-40$ years & 158 & $45.4 \%$
\end{tabular}


Sex

$$
\begin{gathered}
\text { Male } \\
\text { Female }
\end{gathered}
$$

Residence

$$
\begin{aligned}
& \text { Rural } \\
& \text { Urban }
\end{aligned}
$$

Family size

$$
\begin{aligned}
& \leq 5 \text { family members } \\
& >5 \text { family members }
\end{aligned}
$$

Marital status

$$
\text { Single/ never married }
$$

Married

$$
\text { Others } * 1
$$

Ethnicity

$$
\begin{aligned}
& \text { Oromo } \\
& \text { Amhara } \\
& \text { Others } *^{2}
\end{aligned}
$$$$
230
$$$$
66.1
$$

100

28.7

18

Educational Level

$$
\begin{gathered}
\text { No Formal education } \\
\text { Primary (1-8) } \\
\text { Secondary (9-12) } \\
\text { College and above }
\end{gathered}
$$

Occupation

Farmer

House Wife

Merchant

Gov't Employee

Student
78

92

51

66

55
22.4

26.4

14.7

19.0

15.8 
Monthly Income

$\begin{array}{ccc}\text { less than 500 ETB } & 147 & 42.2 \\ 501-1500 \text { ETB } & 35 & 10.1 \\ 1501-3000 \text { ETB } & 90 & 25.9 \\ \text { greater than 3001 ETB } & 76 & 21.0\end{array}$

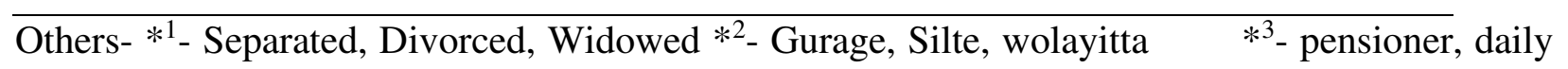
laborer

Characteristics

H. Pylori

Positive No. $(\%) \quad$ Negative No. (\%)

Age Category

$\begin{array}{cll}18-25 \text { years } & 44(41.5 \%) & 60(59.5 \%) \\ 26-40 \text { years } & 82(51.9 \%) & 76(48.1 \%) \\ \geq 41 \text { years } & 40(46.5 \%) & 46(53.5 \%)\end{array}$

Sex

$\begin{array}{cll}\text { Male } & 61(46.9 \%) & 69(53.1 \%) \\ \text { Female } & 105(48.2 \%) & 113(51.8 \%)\end{array}$

Residence

$\begin{array}{lll}\text { Rural } & 64(41.8 \%) & 89(58.2 \%) \\ \text { Urban } & 102(52.3 \%) & 93(47.7 \%)\end{array}$

Marital status

\begin{tabular}{cll} 
Single & $36(40.4 \%)$ & $53(59.6 \%)$ \\
Married & $118(49.6 \%)$ & $120(50.4 \%)$ \\
Separated & $8(61.5 \%)$ & $5(38.5 \%)$ \\
Widower/ widow & $4(50.0 \%)$ & $4(50.0 \%)$ \\
\hline
\end{tabular}


Ethnicity

$\begin{array}{lll}\text { Oromo } & 105(45.7 \%) & 125(54.3 \%) \\ \text { Amhara } & 50(50.0 \%) & 50(50.0 \%) \\ \text { Others*1 } & 11(61.1 \%) & 7(38.9 \%)\end{array}$

№ family members

$$
\begin{array}{lll}
\leq 5 \text { family members } & 113(51.1 \%) & 104(48.9 \%) \\
>5 \text { family members } & 53(41.2 \%) & 78(58.8 \%)
\end{array}
$$

Educational attainment

$\begin{array}{ccc}\text { No Formal education } & 34(47.8 \%) & 37(52.1 \%) \\ \text { Primary (1-8) } & 46(46.0 \%) & 54(54.0 \%) \\ \text { Secondary (9-12) } & 46(47.4 \%) & 51(52.6 \%) \\ \text { College and above } & 40(50.0 \%) & 40(50.0 \%)\end{array}$

Occupation

$\begin{array}{cll}\text { Farmer } & 30(38.5 \%) & 48(61.5 \%) \\ \text { House Wife } & 48(52.2 \%) & 44(47.8 \%) \\ \text { Merchant } & 21(41.2 \%) & 30(58.8 \%) \\ \text { Gov't Employee } & 42(63.3 \%) & 24(36.7 \%) \\ \text { Student } & 21(38.2 \%) & 34(61.8 \%) \\ \text { Other*2 } & 4(66.6 \%) & 2(33.4 \%)\end{array}$

Monthly income (Median)

$\begin{array}{cll}\text { less than } 500 \mathrm{ETB} & 69(46.9 \%) & 78(53.1 \%) \\ 501-1500 \mathrm{ETB} & 19(54.3 \%) & 16(45.7 \%) \\ 1501-3000 \mathrm{ETB} & 41(45.5 \%) & 49(54.5 \%) \\ \text { greater than } 3001 \mathrm{ETB} & 37(48.7 \%) & 39(51.3 \%)\end{array}$

Magnitude of H. pylori infection concerning socio-demographic characteristics among adult dyspeptic patients attending Bokoji Hospital, 2019.

Others- *1- Gurage, Wolayitta, Silte *2- Daily laborer, Pensioner

The magnitude of $\mathbf{H}$. pylori infection concerning environmental factors among adult dyspeptic patients attending Bokoji Hospital.

The magnitude of the infection in participants who obtain drinking water from the river or rainwater was $16(51.6 \%)$. Among study participants of 321 who had toilets about 154 (48.0\%) 
were infected with H. pylori. In participants that do have toilets without a handwashing facility nearby about $136(47.2 \%)$ were positive for H. pylori (Table 3).

Table 3: Magnitude of $H$. pylori infection concerning environmental factors among adult dyspeptic patients attending Bokoji Hospital, 2019.

H. pylori

Positive No. (\%) Negative No. (\%)

Drinking water source

$\begin{array}{cll}\text { Tap water } & 129(46.7 \%) & 147(53.3 \%) \\ \text { River /Rainwater } & 16(51.6 \%) & 15(48.4 \%) \\ \text { Well/spring } & 21(51.2 \%) & 20(48.8 \%)\end{array}$

Availability of Toilet

$\begin{array}{lll}\text { Yes } & 154(48.0 \%) & 167(52.0 \%) \\ \text { No } & 12(42.3 \%) & 15(57.7 \%)\end{array}$

Handwashing Facility $(\mathrm{n}=258)$

$\begin{array}{lll}\text { Yes } & 30(50.0 \%) & 30(50.0 \%) \\ \text { No } & 136(47.2 \%) & 152(52.8 \%)\end{array}$

The magnitude of $\mathrm{H}$. pylori infection about behavioral factors among adult dyspeptic patients attending Bokoji Hospital.

The magnitude of $\mathrm{H}$. pylori infection in participants who did not regularly wash their hands both before a meal and after toilet use was 11 (42.3\%) and 115 (57.2\%), respectively. The positivity rate for $\mathrm{H}$. pylori infection in this study was 62 (57.9\%) among those used to drink alcohol and $63.6 \%$ among those who smoke a cigarette (Table 4 ).

Table 4: Magnitude of $H$. pylori infection concerning behavioral factors among adult dyspeptic patients attending Bokoji Hospital, 2019.

\section{H. Pylori}

Characteristics

Positive No. (\%)

Negative No. (\%)

Hand washing before meal regularly

Yes

$155(48.1 \%)$

$167(51.9 \%)$ 


\section{No}

$11(42.3 \%)$

$15(57.7 \%)$

Hand washing after meal regularly

$\begin{array}{lll}\text { Yes } & 158(49.2 \%) & 163(50.8 \%) \\ \text { No } & 8(29.6 \%) & 19(70.4 \%)\end{array}$

Hand washing habit after toilet
Yes
$51(34.7 \%)$
$96(65.3 \%)$
No
$115(57.2 \%)$
$86(42.7 \%)$

Eating uncooked vegetable habit

$\begin{array}{lll}\text { Yes } & 76(47.5 \%) & 84(52.5 \%) \\ \text { No } & 90(47.9 \%) & 98(52.1 \%)\end{array}$

The habit of eating spicy food
Yes
$8(57.1 \%)$
$6(42.9 \%)$
No
$158(47.3 \%)$
$176(52.7 \%)$

Open field defecation

$\begin{array}{lll}\text { Yes } & 25(48.1 \%) & 27(51.9 \%) \\ \text { No } & 141(47.6 \%) & 155(52.4 \%)\end{array}$

Alcohol drinking habit

$\begin{array}{lll}\text { Yes } & 62(57.9 \%) & 45(42.1 \%) \\ \text { No } & 104(43.2 \%) & 137(56.8 \%)\end{array}$

Cigarette smoking habit

$\begin{array}{lll}\text { Yes } & 7(63.6 \%) & 4(36.4 \%) \\ \text { No } & 166(47.7 \%) & 182(52.3 \%)\end{array}$

\section{The magnitude of $\mathrm{H}$. pylori infection about biophysical factors among adult dyspeptic patients attending Bokoji Hospital.}

Regarding biophysical factors, about $48.2 \%$ of participants with normal body mass index (18.5 $\left.24.9 \mathrm{Kg} / \mathrm{m}^{2}\right)$ and $50 \%$ with underweight $\left(<18.5 \mathrm{Kg} / \mathrm{m}^{2}\right)$ were infected by H. pylori. About $58.3 \%$ of dyspeptic patients with blood group $\mathrm{AB}$ were found positive for $\mathrm{H}$. pylori. Also, 58.9\% of study participants were co-infected with $\mathrm{H}$. pylori and at least one intestinal parasite (Table 5). 
Table 5: Magnitude of $\mathrm{H}$. pylori infection concerning biophysical factors among adult dyspeptic patients attending Bokoji Hospital, 2019.

H. pylori

Positive No. (\%) Negative No. (\%)

BMI $\left(\mathrm{Kg} / \mathrm{m}^{2}\right)$

Less than 18.5

$7(50.0 \%)$

$7(50.0 \%)$

18.5-24.9

Greater than 25

$133(48.2 \%)$

$143(51.8 \%)$

$26(44.8 \%)$

$32(55.2 \%)$

Blood group
A

$\mathrm{AB}$

$\mathrm{B}$

$\mathrm{O}$
$44(50.0 \%)$

$21(58.3 \%)$

$42(51.9 \%)$

$59(41.2 \%)$
$16(41.1 \%)$

Yes

$23(58.9 \%)$

$143(46.3 \%)$
$44(50.0 \%)$

$15(41.2 \%)$

$39(48.1 \%)$

$84(58.8 \%)$
Presence of intestinal parasites

No

\section{Factors associated with $\mathbf{H}$. pylori infection.}

In multivariable binary logistic regression analysis, after controlling for possible cofounders, the habit of handwashing after visiting toilet (AOR 2.241 95\% CI (1.410, 3.563) and alcohol drinking habit (AOR 1.796, 95\% CI $(1.087,2.968)$ were factors significantly associated with infection with H. pylori (Table 6). 


\begin{tabular}{|c|c|c|c|c|}
\hline \multirow[t]{2}{*}{ Characteristics } & \multicolumn{2}{|c|}{ H. pylori status } & \multirow[b]{2}{*}{ COR (95\% C.I) } & \multirow[b]{2}{*}{ AOR (95\% C.I) } \\
\hline & Positive & Negative & & \\
\hline \multicolumn{5}{|l|}{ Residence } \\
\hline Rural & 64 & 89 & $.656(.428,1.005)$ & $.657(.393,1.100)$ \\
\hline Urban & 102 & 93 & 1 & 1 \\
\hline \multicolumn{5}{|c|}{ Marital status } \\
\hline Single & 36 & 53 & 1 & 1 \\
\hline Married & 118 & 120 & $1.448(.884,2.372)$ & $1.674(.957,2.929)$ \\
\hline Separated & 8 & 5 & $2.356(.713,7.781)$ & $3.151(.831,11.944)$ \\
\hline Widowed & 4 & 4 & $1.472(.346,6.271)$ & $1.373(.266,7.095)$ \\
\hline \multicolumn{5}{|c|}{ Family size family member } \\
\hline$\leq 5$ & 113 & 104 & 1 & 1 \\
\hline$>5$ & 53 & 78 & $.625(.403, .970)$ & $.626(.372,1.055)$ \\
\hline \multicolumn{5}{|c|}{ Hand washing after the meal } \\
\hline Yes & 158 & 163 & 1 & 1 \\
\hline No & 8 & 19 & $.434(.185,1.021)$ & $.509(.205,1.262)$ \\
\hline \multicolumn{5}{|c|}{ Hand washing habit after } \\
\hline \multicolumn{5}{|l|}{ toilet } \\
\hline Yes & 51 & 96 & 1 & 1 \\
\hline No & 115 & 86 & $2.517(1.621,3.907)^{*}$ & $2.241(1.410,3.563)^{*}$ \\
\hline \multicolumn{5}{|c|}{ Alcohol drinking habit } \\
\hline Yes & 62 & 45 & $1.815(1.145,2.877)^{*}$ & $1.796(1.087,2.968)^{*}$ \\
\hline No & 104 & 137 & 1 & 1 \\
\hline \multicolumn{5}{|c|}{ Blood group } \\
\hline A & 44 & 44 & 1 & 1 \\
\hline $\mathrm{AB}$ & 21 & 15 & $1.400(.640,3.064)$ & $1.371(.594,3.168)$ \\
\hline B & 42 & 39 & $1.077(.589,1.970)$ & $1.064(.556,2.035)$ \\
\hline $\mathrm{O}$ & 59 & 84 & $.702(.412,1.198)$ & $.616(.346,1.097)$ \\
\hline
\end{tabular}


Presence of intestinal

parasites

$\begin{array}{lllll}\text { Yes } & 23 & 16 & 1.669(.849,3.281) & 1.854(.894,3.845) \\ \text { No } & 143 & 166 & 1 & 1\end{array}$

Table 6: Bi-variable and multivariable binary logistic regression analysis of $\mathrm{H}$. pylori infection with the selected variables among adult dyspeptic patients attending Bokoji hospital, 2019. 


\section{DISCUSSION}

Helicobacter pylori epidemiology globally varies markedly in magnitude and associated factors from place to place and among the population. Therefore, knowing the magnitude of H. pylori infection is essential for intervention strategies accordingly.

In this study, the magnitude of $\mathrm{H}$. pylori infection among adult dyspeptic patients was $47.7 \%$ (95\% CI: $42.45,52.95 \%)$ which is comparable with previous reports $46 \%$ in Dutch [18] and 52.2\% in Mexico [19]. The magnitude of the infection in the current study was greater than $37.9 \%$ from Canada[20]. This could be explained by poor living conditions that favor H. pylori transmission in developing countries as compared to a Canadian study.

On the other hand, the magnitude found in this study was lower than studies in Portugal 84.2\% [21], in Turkey 82.5\% [22], in Korea 54.4\% [23], in China 63.4\% [24], in India 58\% and 62\% [25, 26], in Kazakhstan 76.5\% [27] and in Bhutan 73.4\% [28].

Similarly, the magnitude of the infection in the current study was lower than those reported from African countries such as 75.5\% in Morocco [29], 65 \% Tanzania [30], and 80\% in Nigeria [31] and comparable with finding 56.5\% reported from Libya [32]. On the contrary, the higher magnitude was observed than $12.5 \%$ reported from another study in Nigeria [33].

The variation in the magnitude of $\mathrm{H}$. pylori might be due to differences in diagnostic methods used and risk factors across the geographic location.

The current study showed a lower magnitude of $\mathrm{H}$. pylori infection when compared with most studies conducted in different parts of Ethiopia. Among these in Debretabor 72.2\% [34], in Bahir Dar 63\% [35], in Gondar 65.7\% to 85.6\% [36, 37] and in Asosa 58.3\% [38]. While comparable with results in Butajira 52.4\% [14], in Jinka $50.7 \%$ [39] and in Bahir Dar 41.6\% [40].

The effect of proton pump inhibitor or antibiotic drugs used by the dyspeptic patients as a treatment might have influenced the results. It seemed that patients might have the difficulty of recalling the past 2 weeks of drug intake which might have influenced the stool antigen test results. In this study, the test kits used for the diagnosis of $\mathrm{H}$. pylori were coated with a monoclonal antibody which is specific to a single epitope of the bacterial antigen. This could have reduced the positivity of the test contributing to the magnitude of $\mathrm{H}$. pylori in this study. The other possible explanation for the 
lower magnitude of $\mathrm{H}$. pylori infection found in the current study might be due to the diagnostic test method used. Most studies used the detection of H. pylori in serum, which might show overestimation of the actual frequency since serology cannot differentiate current infection from past infection or antibody against $\mathrm{H}$. pylori may circulate in the blood for a longer time.

Another major finding of the current study was the magnitude of $\mathrm{H}$. pylori infection among participants was independently predicted by the habit of hands washing after visiting the toilet. Thus individuals who did not have handwashing habits after toilet use were almost two times more likely to have H. pylori infection. This finding was similar findings with that reported from Asosa in Ethiopia [38]. The significant association between habits of hand washing after toilet use and H. pylori infection suggest that transmission of $\mathrm{H}$. pylori can result from the fecal-oral route that can relate to poor hygienic practices (handwashing).

The magnitude of $\mathrm{H}$. pylori infection two times more likely among participants who used to drink alcohol which is consistent with other studies reported that regular alcohol drinkers are to be infected by $\mathrm{H}$. pylori $[22,41]$. In contrast, in one study, regular alcohol drinking was observed as a protective factor for $\mathrm{H}$. pylori infection, which suggests all of those who never drink alcohol, those who had only tried in the past and the occasional drinkers had a higher risk than regular alcohol consumers [22]. On the other hand, the consumption of little alcohol might protect infected against Helicobacter pylori bacteria [39].

\section{Conclusion and recommendation}

The magnitude of the H. Pylori infection among patients with dyspepsia in this study was $47.5 \%$ and associated with handwashing habits after visiting the toilet and alcohol drinking habit. This implies that it is a public health problem.

Health professionals should promote the importance of personal hygiene including regular hand washing after visiting the toilet to combat the fecal-oral transmission.

The Woreda Health Office could plan and strengthen awareness creation programs on the transmission routes and prevention mechanisms of $\mathrm{H}$. pylori infection to reduce the burden. Other researchers could conduct community-based studies in the general population to understand the burden of the infection since the infection is mostly asymptomatic. 


\section{Author details}

${ }^{1}$ Department of medical laboratory Sciences, College of Health Sciences, Arsi University

${ }^{2}$ Asella Town Health Office.

${ }^{3}$ Department of Public Health, College of Health Sciences, Arsi University.

\section{Authors' contributions}

All Authors were contributed to the study design, writing original draft, reviewing and editing paper, data entry, analysis and interpretations, read and approve the final manuscript.

\section{Acknowledgments}

We would like to express our deepest gratitude to Arsi University, college of health sciences, Department of public health for all the efforts. We are also very happy to thank Mr. Abdumalik Aliyi, Bokoji Hospital Chief executive officer and all staff for their unreserved help to facilitate administrative supports during the research work. Last but not the least, We would like to extend our thanks to data collectors, supervisor and all research participants who took part in the study.

\section{Ethical Approval and consent form}

Official Ethical Clearance was secured before the commencement of the study from Research ethical Review Board of Arsi University College of Health Science. All Participants of the study were given full information about the objective of the study and signed written informed consent in this study.

\section{Consent for publication}

Not applicable.

\section{Competing interests}

The authors declare that they have no competing interests.

\section{Availability of data and materials}

All data and material will be available upon requests to the corresponding author.

\section{Funding}


This work was supported by Arsi University College of Health Science, Research and Community Service Director.

\section{References}

1. Marshall, B.J. and J.R. Warren, Unidentified curved bacilli in the stomach of patients with gastritis and peptic ulceration. . Lancet, 1984. 1: p. 4.

2. Yvonne, V.D. and J. Rob de, Transmission of Helicobacter pylori: A role for food? Bulletin of the World Health Organization., 2001. 79: p. 6.

3. IARC, Helicobacter pylori eradication as a strategy for preventing gastric cancer., in Available from: http://www.iarc.fr/en/publications/pdfsonline/, I.A.f.R.o.C.H.p.W. Group, Editor. 2014, International Agency for Research on Cancer: Lyon, France.

4. Makola, D., D.A. Peura, and S.E. Crowe, Helicobacter pylori Infection and Related Gastrointestinal Diseases. Journal of Clinical Gastroenterology, 2007. 41(6): p. 11.

5. Frederick, J.H. and A.W. Richard, Helicobacter pylori: Review and Update. Hardin \& Wright : Helicobacter pylori 2002: p. 9.

6. Fuccio, L., L.H. Eusebi, and F. Bazzoli, Gastric cancer, Helicobacter pylori infection and other risk factors. World Journal of Gastroenterology, 2010. 2(9): p. 6.

7. Zhang, R.G., et al., Role of Helicobacter pylori infection in pathogenesis of gastric carcinoma. World Journal of Gastrointestinal Pathophysiology, 2016. 7(1): p. 11.

8. Du, L.-J., et al., Helicobacter pylori eradication therapy for functional dyspepsia: Systematic review and meta-analysis. World Journal of Gastroenterology, 2016. 22(12): p. 11.

9. Kusters, J.G., A.H.M.v. Vliet, and E.J. Kuipers, Pathogenesis of Helicobacter pylori Infection. Clinical Microbiology Reviews, 2006. 19(3): p. 42.

10. $\mathrm{MOH}$, Federal Ministry of Ethiopia; Health Health and Health Related Indicators 2005 E.C, P.P. Directorate, Editor. 2014.

11. Ayele, B. and E. Molla, Dyspepsia and Associated Risk Factors at Yirga Cheffe Primary Hospital, Southern Ethiopia. Clinical Microbiology J., 2017. 6(3): p. 8.

12. Asrat, D., et al., Prevalence of Helicobacter pylori vacA and cagA genotypes in Ethiopian dyspeptic patients. Journal of Clinical Microbiology, 2004. 42(6): p. 4.

13. Seid, A., Z. Tamir, and W. Demsiss, Uninvestigated dyspepsia and associated factors of patients with gastrointestinal disorders in Dessie Referral Hospital, Northeast Ethiopia. BMC Gastroenterology, 2018. 18(13): p. 10.

14. Kibru, D., et al., Helicobacter pylori infection and its association with anemia among adult dyspeptic patients attending Butajira Hospital, Ethiopia. BMC infectious disease., 2014. 14(656): p. 7.

15. WHO, Basic Laboratory Methods in Medical Parasitology. Vol. 94. 1991: World Health Organization. Geneva.

16. Cheesbrough, M., District Laboratory Practice in Tropical Countries: part 2. 2006, New York, United States of America Cambridge University Press. 197.

17. WHO, LABORATORY BIOSAFETY MANUAL. Vol. 4. 2003, Geneva, Sewitherland: World Health Organization.

18. Hollander, W.J.d., et al., Ethnicity is a strong predictor for Helicobacter pylori infection in young women in a multi-ethnic European city. Journal of Gastroenterol Hepatol, 2013. 28(11): p. 15.

19. Alvarado-Esquivel, C., Seroepidemiology of Helicobacter Pylori Infection in Pregnant Women in Rural Durango, Mexico. International journal of Biomedical science, 2013. 9(4): p. 6. 
20. Sethi, A., et al., Prevalence of Helicobacter pylori in a First Nations population in northwestern Ontario, Canada. Canadian Family Physician, 2013. 59(182): p. 6.

21. Bastos, J., et al., Sociodemographic Determinants of Prevalence and Incidence of Helicobacter pylori Infection in Portuguese Adults. Helicobacter, 2013. 18(6): p. 4.

22. Ozaydin, N., S.A. Turkyilmaz, and S. Cali, Prevalence and risk factors of helicobacter pylori in Turkey: a nationally-representative, cross-sectional, screening with the 13C-Urea breath test. BMC Public Health, 2013. 13(1): p. 12.

23. Lim, S.H., et al., Prevalence and risk factors of Helicobacter pylori infection in Korea: Nationwide multicenter study over 13 years. BMC Gastroenterology, 2013. 13(104): p. 10.

24. Zhu, Y., et al., Risk Factors and Prevalence of Helicobacter pylori Infection in Persistent High Incidence Area of Gastric Carcinoma in Yangzhong City. Gastroenterology Research and Practice, 2014. 2014: p. 10.

25. Adlekha, S., et al., Prevalence of Helicobacter pylori infection among patients undergoing upper gastrointestinal endoscopy in a medical college hospital in kerala, India. Ann Med Health Sci Res, 2013. 3(4): p. 5.

26. Sodhi, J.S., et al., Prevalence of Helicobacter pylori infection and the effect of its eradication on symptoms of functional dyspepsia in Kashmir India. Journal of Gastroenterol Hepatol, 2013. 28(5): p. 5.

27. Benberin, V., et al., Prevalence of H. pylori Infection and Atrophic Gastritis Among Symptomatic and Dyspeptic Adults in Kazakhstan. A Hospital based Screening Study Using a Panel of Serum Biomarkers. Anticancer Research, 2013. 33: p. 8.

28. Vilaichone, R.-k., et al., Extremely high prevalence of Helicobacter pylori infection in Bhutan. World Journal of Gastroenterology, 2013. 19(18): p. 5.

29. Benajah, D.A., et al., Prevalence of Helicobacter pylori and its recurrence after successful eradication in a developing nation (Morocco). Clinics and Research in Hepatology and Gastroenterology, 2013. 37(5): p. 8.

30. Segni, M.A., et al., Upper gastrointestinal endoscopic findings and prevalence of Helicobacter pylori infection among adult patients with dyspepsia in northern Tanzania. Tanzania Journal of Health Research, 2014. 16(1): p. 9.

31. Olokoba, A., et al., Helicobacter pylori infection in Nigerians with dyspepsia. Ghana Medical Journal, 2013. 47(2): p. 3.

32. A. Almehdawi, K. and R. H. Ali, The Prevalence of Helicobacter Pylori Infection in Benghazi, Libya. Journal of Dental and Medical Sciences, 2016. 15(7): p. 5.

33. Jemikalajah DJ and Okogun GRA, Health point prevalence of Helicobacter pylori In Central Hospital, Warri, Nigeria. African Journal of Cellular Pathology, 2014. 3: p. 4.

34. Abebaw, W., M. Kibret, and B. Abera, Prevalence and Risk Factors of H. pylori from Dyspeptic Patients in Northwest Ethiopia: A Hospital Based Cross-sectional Study. Asian Pacific Journal of Cancer Prevention, 2014. 15(11): p. 5.

35. Tadege, T., et al., Seroprevalence of Helicobacter pylori Infection in and its Relationship with $A B O$ Blood Groups. Ethiop Journal of Health Developement, 2005. 19(1): p. 6.

36. Mathewos, B., B. Moges, and M. Dagnew, Seroprevalence and trend of Helicobacter pylori infection in Gondar University Hospital among dyspeptic patients, Gondar, North West Ethiopia. BMC Research Notes, 2013. 6(346): p. 4.

37. Moges, F., et al., Seroprevalence of Helicobacter pylori in dyspeptic patients and its relationship with HIV infection, ABO blood groups and life style in a university hospital, Northwest Ethiopia. World Journal of Gastroenterology, 2006. 12(12): p. 5. 
38. Dilnessa, T. and M. Amentie, Prevalence of Helicobacter pylori and risk factors among dyspepsia and non-dyspepsia adults at Assosa General Hospital, West Ethiopia: A comparative study. Ethiopian Journal of Health Developement, 2017. 31(1): p. 10.

39. Hailu, G., K. Desta, and F. Tadesse, Prevalence and Risk Factors of Helicobacter pylori among Adults at Jinka Zonal Hospital, Debub Omo Zone, Southwest Ethiopia. Autoimmune and Infectious Diseases, 2016. 2(2): p. 8.

40. Workineh, M. and D. Andargie, A 5-year trend of Helicobacter pylori seroprevalence among dyspeptic patients at Bahir Dar Felege Hiwot Referral Hospital, Northwest Ethiopia. Research and Reports in Tropical Medicine, 2017. 2016(7): p. 6.

41. Hanafia, M.I. and A.M. Mohameda, Helicobacter pylori infection: seroprevalence and predictors among healthy individuals in Al Madinah, Saudi Arabia. Journal of the Egyptian Public Health Association, 2013. 88: p. 6. 